EGTRIB Journal

JOURNAL OF

THE EGYPTIAN SOCIETY OF TRIBOLOGY

VOLUME 19, No. 1, January 2021, pp. 14 - 27 ISSN 2090 - 5882

(Received September 12. 2021, Accepted in final form November 29. 2021)

jest.journals.ekb.eg

\title{
SURVEY OF GEAR FAULT DIAGNOSIS USING VARIOUS STATISTICAL SIGNALS PARAMETERS
}

\author{
Samuel D. Y. ${ }^{1}$, Nabhan A. ${ }^{2}$ and Mousa M. O. ${ }^{2}$ \\ ${ }^{1}$ Mechatronics Program, Faculty of Engineering, Minia University, El-Minia 61111, EGYPT, \\ ${ }^{2}$ Production Engineering and Mechanical Design, Faculty of Engineering, Minia \\ University, El-Minia 61111, EGYPT.
}

\begin{abstract}
Gears are critical components of industrial equipment, where gear failure results machinery failure and that consider as a significant reduction in productivity. It is always critical to keep track of the machine's health in time. Consequently, researchers have been working on developing methods for identifying and diagnosing gear problems. The purpose of this paper is focused to provide a review of a variety of diagnosis techniques that have been shown to be successful when applied to rotating machinery such as gears, as well as to highlight fault detection and identification techniques that are primarily based on vibration analysis. fluctuations from these standards generate distinctive vibration signals whose help in monitoring the gearbox malfunctions. The main sources of these fluctuations are crack tooth, chipped tooth, missing tooth, the surface wear during heat treatment or gearbox assembly, and the geometrical errors, resulting from the gear cutting process and wear. In conclusions, a brief explanation of a novel method of diagnosis based on hybrid artificial intelligence approaches that incorporate neural networks, fuzzy sets, expert systems, and fault detection is provided.
\end{abstract}

\section{KEYWORDS}

Condition monitoring, gearbox, vibration analysis, gear fault, time domain analysis, frequency domain analysis.

\section{INTRODUCTION}

Identifying components that are problematic throughout the manufacturing process is difficult in the present modern manufacturing world. The most essential transmission component, the gear, would be worn out if used continuously. Because of its relevance in any industry, monitoring the operating state of a gearbox or gear system is a crucial job, [1]. The oscillations and its sound produced by all machines with moving parts are distinct, and each machine has a unique vibration signature that is related to the machine's construction and current state. When the state of the machine changes, the vibration signature changes as well, and this change can be utilized to detect developing faults before they become critical. This is the main principles of condition monitoring methods. Condition monitoring can help to save money by increasing maintenance efficiency and lowering the risk of serious accidents through the prevention of breakdown, $[2,3]$.

Gear transmissions system is one of the most common in rotating machinery, which are used to transmit torque between shafts. Failure in gears could affect the overall operation of the machine, [4]. The monitoring is carried out for several purposes to characterize the emitted sound, diagnose faults in running machinery's gearboxes and check 
correctness of gearbox assembly after manufacturing for identifying problems if any, before clearing it for use in any vehicle or machine, [5, 6]. Also, the effect of bearing defects on vibration is modeled using simulation method, [7]. The term of condition monitoring refers to the practice of utilizing advanced technologies to ascertain the state of equipment and to predict potential failure. These technologies include, but are not limited to, visual inspection, temperature monitoring, acoustic emission analysis, noise analysis, oil analysis, wear debris analysis, motor current signature analysis and vibration measurement and analysis, [8].

\section{NECESSITY TO DETECT AND IDENTIFY OF MACHINE FAULTS}

Diagnosis and monitoring of transmission system fault can be consider as any fluctuation in a machinery component which causes a malfunction and the system becomes incapable to accomplish its task, [9]. Diagnosis of an antifriction bearing malfunction is a major factor in transmission system validity condition, especially the fault must be discovered in its initial stages, $[10,11]$. The localized and distributed defects are likely to be produced from manufacturing processes and abrasive debris. The rotary system subjected to resonance frequency, was investigated using a sinusoidal function basis at the first vibration mode. It was found that, the envelope detection method could be a perfect way to perform the bearing defect diagnosis, [12]. A mathematical model was established to detect the defect on the bearing. The results showed that, the amplitude level of vibration signals was produced from outer race defect is more than that for the inner race defect [13]. FE Dynamic model considers a suitable method used to diagnosis the bearing defects of different sizes in the bearing, [14].

Gear faults typically occur in the teeth of a gear mechanism due to surface wear, fatigue, cracks, or pitting. Most gear Fault diagnosis and detection techniques which based on signal response methods via acoustic emission transducers and vibration sensors has been widely investigated, $[15,16]$. A new approach used to detect the faults based on acoustic emission and vibration signals was developed, [17]. It can be indicated from the results that the proposed methods were adequate under various operating conditions, applied loads and fluctuating speeds. A model-based gear fault detection method is preferable to identify the gear defects using transmission error. A parametric model of a gear model was established to estimate the transmission error, [18]. Finite element analysis via ABAQUS is created to estimate the influence of shaft misalignment and backlash on the stress generated on the spur gear, [19]. Malfunction belt drive system monitor and detect using vibration analysis techniques, [20]. The belt drive experimental equipment was performed to obtain realistic vibration signals under different operating conditions. The pulley-belt system faults like unbalance, misalignment and mis-cogs, that dedicated by vibration analysis technique, $[21,22]$. The unstable belt transmission was studied via the perturbation solution under assumptions of the forces applied is the same on the stick-slip regions. It can be observed that the results showed a good agreement with numerical solutions, $[23,24]$. The results of statistical parameters explained the effect of each type of faults comparing with the ideal system conditions. A numeric model of the belt drive system is established using ABAQUS to study the system transmission error under unsteady operating conditions, $[25,26]$.

\section{GEAR AND GEAR FAULT}

The motion and power transmitted by gears is kinematically equivalent to that transmitted by frictional wheels or discs. A gear drive is performed, when the distance between the driver and the driven shafts is very small. In precision machines, in which low slipping effect leads to reduce the velocity ratio of the system. Perfect gear meshing and ideal installing of gears do not produce vibration signals. fluctuations from these standards generate distinctive vibration signals whose help in monitoring the gearbox malfunctions. The main sources of these fluctuations are crack tooth, chipped tooth, 
missing tooth, the surface wear during heat treatment or gearbox assembly, and the geometrical errors, resulting from the gear cutting process and wear. Figure 1 illustrates some of the gear faults.

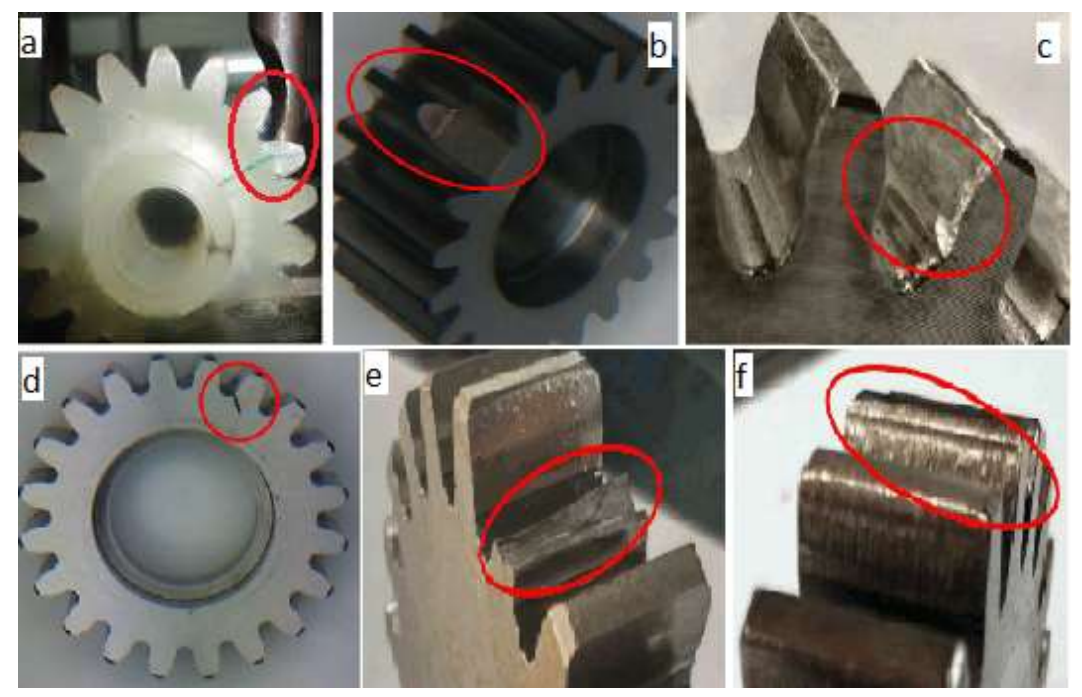

Fig.1. The fault gears. (a) tooth deflection, (b) chipped tooth, (c) pitting tooth, (d) crack tooth, (e) missing tooth (f) surface wear.

\section{CONDITION MONITORING TECHNIQUES}

Each component of the power transmission has a distinct vibration signature related to machine performance and condition. Any change in the state of this component also changes the vibration signature, which makes the vibration response an indication of equipment monitoring. This is the foundation upon which condition monitoring methods are built. Condition monitoring techniques can save time and money through scheduling the maintenance, reduce the accidents risk, prevent a breakdown and extend equipment's lifespan, [2, 27].

\subsection{Visual inspection}

Traditionally, optical/visual inspection has been used as one of the basic tools in detecting deterioration and damage exhibited on the surface as well as the inner integrity of the shaft member. Optical procedures are most frequently used for visual inspection by maintenance staff. However, given that human eyes have limited capabilities, it is difficult to detect damage on-site, even for skilled technicians. Complete machine shutdown and disassembly is often required, [28]. Another disadvantage of scheduled maintenance, or predictive maintenance, is that it tends to replace machines that may continue to function for several years, [29]. Sometimes, in order to double-check results, samples of the structures are extracted and tested in a laboratory to detect if the inspection was accurate. In the meantime, the use of $\mathrm{X}$-ray and thermal imaging procedures has been successful in some smaller shafts. But the applications of these procedures are extremely limited, and the costs of putting them in place on the ground are prohibitively expensive to implement, [30].

\subsection{Acoustic emission analysis}

Acoustic emission is the phenomenon of transient elastic wave generation due to a rapid release of strain energy caused by a structural alteration in a solid material. Generally these structural alterations are the result of mechanical or thermal stress that has been applied either internally or externally, [31]. Gear defects can be detected using a process called AE analysis, which requires the transmission signal path to be as short as possible. This minimizes interferences between mesh of gears signal and other machine parts and emphasizes on useful information about faults. At a gear wheel test bench, to detect and 
locate the source of a defect, acoustic emission sensors were placed on the gearbox casing and on the ends of the rotating shafts in order to detect defects at an early stage. Because of the meshing gear and other embedded components, measuring only the number and intensity of emissions is insufficient. In order to make sure an accurate assessment of the short-time excitations in the frequency domain, we must do additional analysis by using wavelet techniques, [32]. Acoustic emission (AE) has long been recognized as a highly effective method for non-destructive monitoring and damage detection. While traditional AE monitoring techniques such as ultrasound are capable of accurately locating incipient damage in structural members, their application to rotating structures has been limited due to the requirement for a large number of connecting wires to be attached to the rotating shaft, [33].

\subsection{Oil-debris Monitoring}

Another commonly used condition monitoring-based approach for fault prediction is the oil-debris monitoring method. Transmission failures, such as gear and bearing failures, generate a significant amount of wear debris in the oil lubrication system. When damage begins to occur, the amount of debris measured by an oil debris monitor will increase, [34]. Typically, a machine's wear process is the result of several distinct, concurrent wear mechanisms, each of which has its own unique effect on the machine's operating environment and the changes that occur in it. The wear and the dynamic forces could cause the machine parts to break or upset the machine's operation if the unfavorable operating conditions persist. To control the wear process, an early detection system must be used as well as a system to monitor the size, amount, and appearance of wear debris particles in the machine's lubricating oil, [35, 36]. A variety of on-line methods are available for oil debris monitoring, $[37,38]$. Some of the principles of the various methods are Ferrography, [39, 40], ultrasonic, [41], and X-ray fluorescence (XRF), [42].

\subsection{Temperature Monitoring}

Temperature monitoring is comprised of the measurement of the operational temperature as well as the temperature of component surface temperatures. It is possible to think of monitoring operational temperature as a subset of the operational variables for performance , [43]. The monitoring of component temperature has been found to be related to wear occurring in machine elements where lubrication is either insufficient or absent. The techniques for monitoring temperature of machine components can include the use of optical pyrometers, thermocouples, thermography, and resistance thermometers, [44].

\subsection{Noise Analysis}

For the purpose of condition monitoring, noise signals are used. This is because noise signals measured in regions close to the external surface of machines can contain important information about the internal processes of the machine, as well as valuable information about the machine's operating condition. Machine noise typically has specific spectral characteristics when machines are working well. The frequency spectra change as faults begin to develop. Every frequency component can be traced to a specific machine component. This is the base for noise measurement and analysis in condition monitoring. It is sometimes the case that a particular signal is surrounded by other signals, and the resulting time-series or spectral analysis does not pick it up. When it comes to this particular scenario, specialized signal techniques are required, [8].

\subsection{Motor current signature analysis}

Motor current signature analysis (MCSA) is a novel diagnostic technique used to monitor the condition of mechanical equipment powered by electric motors such as (pumps, motor-operated valves, compressors, and processing machinery). The MCSA 
process uses a set of measurements to identify, characterize, and track minute-to-minute changes in the condition of mechanical equipment in order to diagnose any equipment problems. It detects the rapid changes in the amount of noise in the power current flowing to the motor that powers the equipment. Because the motor is a transducer, it translates mechanical loads, which vary in terms of their size, time frame, and load intensity, into electrical variations in the current generated in the motor windings. Detection of the motor current noise signature, amplification of the noise signature, and further processing as needed are performed to examine the time-domain and frequencydomain (spectral) characteristics of the noise signature. Finds that by using Fast Fourier transformation, it is possible to analyze the motor current and voltage signals and still keep the motor running without disturbing its operation, [45]. Neural network has also been used to study motor current data for the diagnosis of a planetary gearbox defect. Data relevant to the motor current spectrum was extracted and used to train a deep neural network for the diagnosis of a planetary gearbox defect, all of this will be discussed briefly at the end of the paper, [46].

Table 1. Condition monitoring indicators of gear fault detection

\begin{tabular}{l|l|l}
\hline Condition Indicators & \multicolumn{1}{c}{ Faults } & References \\
\hline Visual inspection & Non-circular gear, tooth profile error & {$[28]-[30][47]$} \\
\hline AE analysis & General fault progression primitively & {$[31],[32][48]$} \\
\hline Oil-debris lonitoring & Wear, breakage & {$[34]-[42]$} \\
\hline Temperature Monitoring & Wear, Lubrication & {$[44][49]$} \\
\hline Noise Analysis & Erroneous operating conditions & {$[8][33]$} \\
\hline MC signature analysis & Fluctuation in gear load, predict a model built & {$[45],[46][50],[51]$} \\
\hline
\end{tabular}

\section{VIBRATION ANALYSIS}

Vibration analysis is a superior method for diagnosing faults in rotating components by comparing the vibration signal to other variables such as wear, sound, and temperature, [1]. The concept of source-path-receiver is fundamental to an understanding of vibrations, [52]. A machine's oscillatory motion is a response to exciting forces that may originate internally or externally to the machinery unit. Internal sources include rotor imbalance, coupling or bearing misalignment, and worn or damaged mating components such as gears, all of these are examples of material or alignment defects that can be corrected to reduce the amplitude of the forces generated. External sources include load variations, flow conditions, and vibration of adjacent structures or equipment, all of these are examples of issues that cannot be attributed to a physical defect in the machinery unit. The transmission of forces from their sources occurs in one of two ways that are of primary interest to the vibration analyst: mechanical transmission of forces between components, or acoustic emissions emanating from each component set into vibratory motion.

Mechanical and acoustic signals are the two fundamental types of signals that can be measured and analyzed, and they correspond to the two general fields that have developed. Although the instrumentation employed for each of these two signal types is different, the fundamentals of the signal analyses follow a similar path. There is no need to shut down the rotating machinery when performing the signals analysis procedures described above, and the results of the signals analysis procedures can be used as an online diagnostic and trend monitoring tool. The study and development of measurement and analysis techniques for vibration signal analysis is a logical choice for a field to investigate and develop in order to serve as natural extensions of those fundamental human senses that are inherently more responsive to and thus more informative about the condition of machinery, [53]. These methods can be classified into time domain analysis and frequency domain analysis. The three main stages of the vibration-based fault detection process can be explained as follows, [54 - 56]: 
- Data acquisition (data space): vibration signal data collection performed through experiments or theoretically using dynamic models and simulation.

- Data processing (feature space): vibration signal data processing for feature extraction.

- Failure pattern recognition (fault space): analysis of the extracted features for assessment of the machine condition.

5.1. Time domain analysis

5.1.1. Waveform analysis

The time domain was used for almost all vibration analysis before spectral analyzers became commercially available. It was often possible to detect changes in the vibration signature caused by faults by studying the time domain waveform with equipment such as oscilloscopes. However, a very difficult task to diagnose faults. Determining the change required measuring the repetition frequency of a particular component with the aid of the time difference detected between feature points, [57].

\subsubsection{Time domain signal metrics}

Although detailed study of the time domain waveform is no longer widely used, several simple signal metrics based on the time domain waveform continue to be widely used in mechanical fault detection. These simple signal metrics are referred to as feature extraction. These features are referred to as time domain features because they are characteristics of the actual time domain signal. Additionally, performing analysis on the acquired raw data requires a significant amount of computational time since it involves processing a large amount of data. The computational time can be reduced by utilizing the features extracted from the time-domain signal, [4]. Statistical features extraction like mean, peak value, root mean square value, crest factor value, kurtosis value, etc. are extracted to describe the characteristics of the time waveform in the time-domain analysis, [54].

\subsubsection{Peak}

The peak level of the signal is defined as: half the difference between the maximum and minimum vibration levels:

$$
\text { Peak }=\frac{1}{2}\left(\max \left(x_{(t)}\right)-\min \left(x_{(t)}\right)\right)
$$

The peak level is not solid in detecting faults continuously operating systems because it's not statistical quantity, [57 - 59].

\subsubsection{Root Mean Square (RMS)}

Root Mean Squared (RMS) method is the simplest and most straightforward way to find and measure faults in the time domain. This tool is helpful in keeping track on general noise levels. Unbalanced rotating elements can also be detected by means of this value. The root mean squared, also known as a quadratic mean, is a statistical measure of the magnitude of a varying quantity. RMS was originally developed to describe the temperature of a resistor when it was subjected to sine wave alternative current. In the vibration signature, the root mean squared value of the signal is a time analysis feature that is a measure of the power continent. It is particularly useful in the case of sinusoidal waves. RMS of a sine wave can be defined as 0.707 times the amplitude of the signal. RMS of a signal sample can be calculated as the square root of the average of the sum of the squares of the signal samples, [60 - 61].

$$
R M S=\sqrt{\frac{1}{N}\left[\sum_{i=1}^{N}\left(x_{i}\right)^{2}\right]}
$$

Where, $x$ is the original sample time signal, $N$ is the number of samples taken and $i$ is the sample index.

\subsubsection{Crest Factor}

The crest factor is defined as the ratio of the peak value to the RMS of the signal: 


$$
\text { Crest Factor }=\frac{P e a k}{R M S}
$$

This measurement technique gives more accurate results than RMS when it comes to detecting faults with rotating machinery. Impulsive vibration sources can change the signal pattern, and this value is used to detect these changes. The crest factor value increases as the number of peaks in the time series signal increases, as is the case with impulsive vibration sources such as a gear tooth breaking. This method is not regarded as a particularly delicate one. It is vital to understand that when a gear tooth is damaged, the RMS value of the damaged gear does not increase during one revolution, but the peak value will increase, $[7,62]$. So, crest factor will also increase but as damage becomes severe, RMS value will also increase with increase in peak value, in that case crest factor value will decrease. This feature's uniqueness enables it to detect very minor surface damage.

\subsubsection{Kurtosis}

This technique provides a measure of the size of the tails of distribution. It can be used to identify significant peaks in a signal, [63]. The kurtosis can be defined as the fourth normalized moment of the signal. The fourth moment is normalized using the variance's square, [64]. It is useful measurement of the peakedness of a signal, [65]. As gear wears or breaks, this feature should indicate an error as the level of vibration increases, [66]. Simply, kurtosis is a statistical measure of the number of peaks in a signal's amplitude. When a signal contains more peaks, the kurtosis value increases.

A Gaussian noise signal has a kurtosis value close to three. If the gearbox is in good condition, it will have a Gaussian distribution and will have a kurtosis of approximately three. It should be noted that researchers subtract three from the calculated value and they end up with a value of near zero for a healthy gearbox. Kurtosis equation is given by,

\subsection{Frequency domain analysis}

$$
\text { Kurtosis }=\frac{N \sum_{i=1}^{N}\left(x_{i}-\bar{x}\right)^{4}}{\left[\sum_{i=1}^{N}\left(x_{i}-\bar{x}\right)^{2}\right]^{2}}
$$

Every signal in the real world can be broken down into a number of unique sine waves as illustrates in Fig. 2. Every sine wave that is separated from the signal appears as a vertical line in the frequency domain. A wave's amplitude is represented by the height, and the frequency is represented by the position. The vibration is completely defined by the frequency domain. Frequency domain analysis not only detects faults in rotating machinery, but it also identifies the cause of the fault, [67].

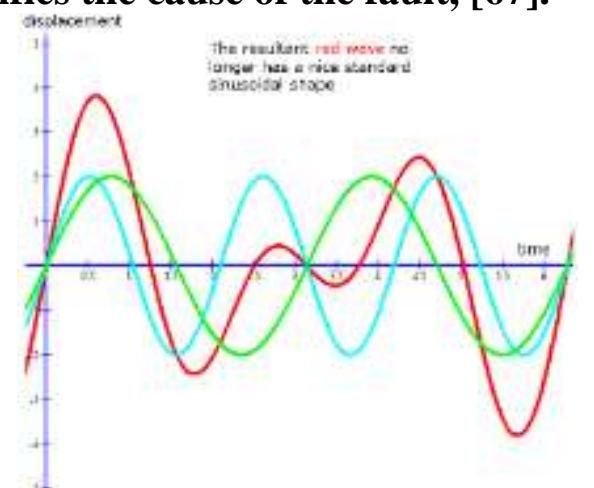

Fig. 2. Combination of unique sine waves

Figure 2. shows a view of the three-dimensional graph along the time axis, here, we have amplitude versus frequency axes. This is referred to as the frequency domain. Each sine wave that we extracted from the input is represented by a vertical line. Its height indicates its amplitude, while its position indicates its frequency. It can be known that each line represents a sine wave, and thus our input signal has been uniquely characterized in the frequency domain. This frequency domain representation of our 
signal is called the spectrum of the signal, [68]. This frequency domain representation of our signal is called the spectrum of the signal. Each sine wave line of the spectrum is called a component of the total signal. To analyze the frequency distribution of vibration waveforms, the time domain signal must be transformed into the frequency domain using the Fast Fourier Transform (FFT), [69].

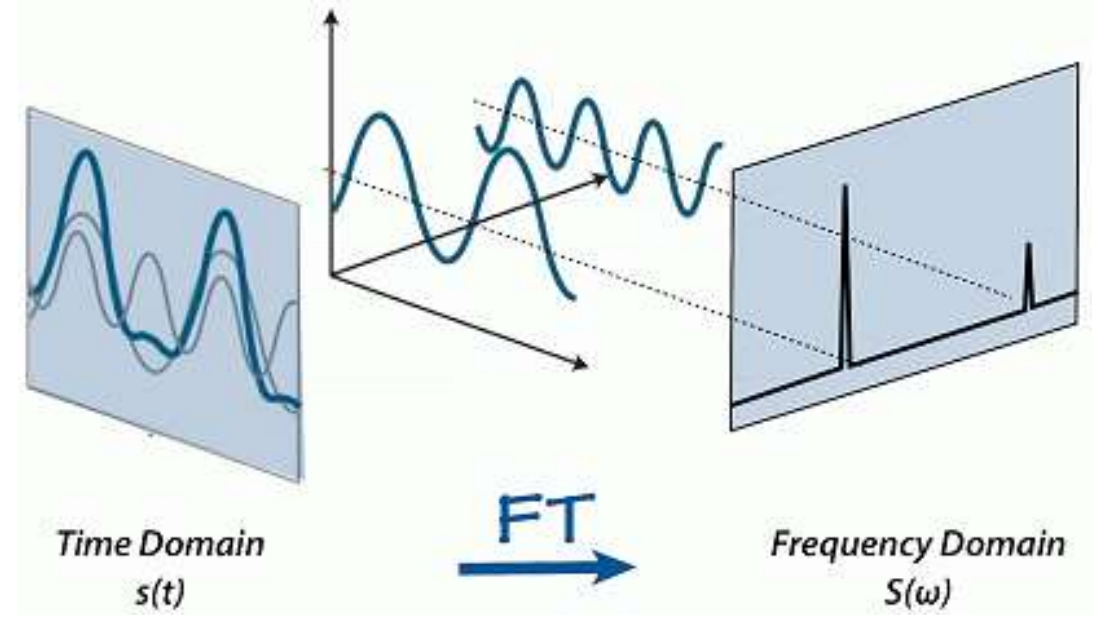

Fig. 3. Fourier Transformation of time domain signal to frequency domain.

\subsubsection{Spectral analysis}

Spectral (or frequency) analysis is a term that refers to the examination of a signal's frequency domain representation. The most frequently used vibration analysis technique for condition monitoring in geared transmission systems is spectral analysis, which has proven to be an invaluable tool for detecting and diagnosing faults in simple rotating machinery [70]. While the overall vibration level is a measure of the vibration produced across a broad band of frequencies, the spectrum is a measure of the vibrations produced across many discrete contiguous narrow frequency bands. The fundamental operation shared by all spectral analysis techniques is the conversion of the vibration signal's time domain representation to a frequency domain representation. This can be achieved by the use of narrow band filters or, more recently, through the use of digitized data and the discrete Fourier Transform (DFT) [71]. The vibration level at each 'frequency' represents the vibration over a narrow frequency band centered at the designated 'frequency', with a bandwidth determined by the conversion process employed.

\subsubsection{Conversion to the frequency domain}

Most modern spectrum analyzers use the Fast Fourier Transform (FFT), [72], which is an efficient algorithm for performing a Discrete Fourier Transform (DFT) of discrete sampled data, [73]. The Fast Fourier Transform (FFT) resolves a time waveform into its sinusoidal components. The FFT takes a block of time-domain data and returns the frequency spectrum of the data. The FFT is a digital implementation of the Fourier transform. Thus, the FFT does not yield a continuous spectrum. Instead, the FFT returns a discrete spectrum, in which the frequency content of the waveform is resolved into a finite number of frequency lines, or bins.

\section{ADVANCED SIGNAL PROCESSING TECHNIQUES}

Micro technology and artificial intelligence advancements have accelerated the trend toward more comprehensive onboard diagnostics. Recent systems have incorporated artificial intelligence techniques to bolster diagnostics systems robustness. Four artificial techniques have been widely applied as expert system, neural networks, [74] fuzzy logic, and model-based systems, [75]. The vibration signal is one of the most frequently used signals in the diagnosis of mechanical faults. fault-sensitive features are selected and extracted from raw signal through signal processing technology and dimension reduction strategies, such as Fourier spectral analysis [76 - 77]. In the step of fault classification, 
health conditions are diagnosed based on the extracted features through intelligent classification techniques, such as neural networks (NN), support vector machine (SVM) [78] and self-organizing map (SOM), [79 - 80].

Table 2. Vibration analysis indicators of gear fault detection

\begin{tabular}{|c|c|c|}
\hline Condition Indicators & Faults & References \\
\hline \multicolumn{3}{|l|}{ Time domain analysis } \\
\hline Waveform analysis & Gear-damaged, fault types & {$[57],[58][59]$} \\
\hline TD signal metrics & General fault progression & {$[4],[54][81]$} \\
\hline Peak & Unbalanced rotating elements & {$[57],[58][82]$} \\
\hline RMS & Localized fault, surface damage & {$[14],[25],[60],[61][83]-[85]$} \\
\hline Crest Factor & $\begin{array}{l}\text { Impulsive vibration due to tooth } \\
\text { break }\end{array}$ & {$[7],[62][82]$} \\
\hline Kurtosis & Breakage, wear, misalignment & {$[25],[63]-[66][86]$} \\
\hline \multicolumn{3}{|c|}{ Frequency domain analysis } \\
\hline Spectral analysis & Misalignment, localized fault & {$[70],[71][87],[88]$} \\
\hline Conversion to the FD & Scuffing, pitting & {$[72],[73]$} \\
\hline \multicolumn{3}{|c|}{ Advanced Signal Processing Techniques } \\
\hline Neural networks & Tooth wear, tooth breakage & {$[74][89]-[91]$} \\
\hline Model-based systems & Tooth crack & {$[75][92]-[94]$} \\
\hline $\begin{array}{l}\text { Fourier spectral } \\
\text { analysis }\end{array}$ & $\begin{array}{l}\text { Effectively extract the weak fault } \\
\text { signal }\end{array}$ & {$[76],[77][95]$} \\
\hline Support vector machine & Classifying the faults & {$[78][95]-[97]$} \\
\hline Self-organizing map & $\begin{array}{l}\text { More accurate diagnosis of fault, } \\
\text { pitting }\end{array}$ & {$[79],[80][98],[99]$} \\
\hline
\end{tabular}

\section{CONCLUSIONS}

The purpose of this work is to summarize recent research and developments in the detecting techniques for diagnosing and monitoring gearbox faults. The study of such attribute defects has gained in importance as people have become more aware of the high cost of quality. From the previous study, there are traditional conditions monitoring techniques such as visual inspection, acoustic emission analysis, oil-debris monitoring, temperature monitoring and motor current signature analysis. There are also methods that are currently used such as Vibration analysis and its use in artificial intelligence applications. This study subjected that vibration monitoring is the most advantageous technique due to its reliability and sensitivity to fault severity. Additionally, it provides clear indications of the gearbox's condition. Consequently, the level of vibrations and the frequency at which they occur can be used to determine the precise location and possibly severity of a defect. It can be concluded that the ease with which the vibration analysis technique can be applied makes it the most widely used technique.

\section{REFERENCES}

1. V. Gunasegaran and V. Muralidharan, "Fault diagnosis of spur gear system through decision tree algorithm using vibration signal," Mater. Today Proc., vol. 22, pp. 3232-3239, (2020).

2. J. Wändell, "Multistage gearboxes: Vibration based quality control." KTH, (2006).

3. T. Praveenkumar, B. Sabhrish, M. Saimurugan, and K. I. Ramachandran, "Pattern recognition based on-line vibration monitoring system for fault diagnosis of automobile gearbox," Measurement, vol. 114, pp. 233-242, (2018).

4. L. Bachar, I. Dadon, R. Klein, and J. Bortman, "The effects of the operating conditions and tooth fault on gear vibration signature," Mech. Syst. Signal Process., vol. 154, p. 107508, (2021).

5. P. V Kane and A. B. Andhare, "Application of psychoacoustics for gear fault diagnosis using artificial neural network," J. Low Freq. Noise, Vib. Act. Control, vol. 35, no. 3, pp. 207-220, (2016). 
6. A. A. Deshpande, J. J. Mishrikoti, and V. V Kulkarni, "Vibration Signature Analysis of Reciprocating Element in Machines using MATLAB and LabVIEW," IAETSD J. Adv. Res. Appl. Sci., vol. 5, no. 6, pp. 13-22, (2018).

7. A. Nabhan, M. Nouby, A. M. Sami, and M. O. Mousa, "Vibration analysis of deep groove ball bearing with outer race defect using ABAQUS," J. Low Freq. Noise, Vib. Act. Control, vol. 35, no. 4, pp. 312-325, (2016).

8. P. Jayaswal, A. K. Wadhwani, and K. B. Mulchandani, "Machine fault signature analysis," Int. J. Rotating Mach., vol. ID 583982, (2008).

9. H. P. Bloch and F. K. Geitner, "Machinery Failure Analysis and Troubleshooting, Vol. 2." Gulf Publishing Co, (1999).

10. M. Amarnath, R. Shrinidhi, A. Ramachandra, and S. B. Kandagal, "Prediction of defects in antifriction bearings using vibration signal analysis," J. Inst. Eng. Part MC, Mech. Eng. Div., vol. 85, p. 88, (2004).

11. A. Nabhan, M. Nouby, A. M. Sami, and M. O. Mousa, "Multiple defects detection in outer race of gearbox ball bearing using time domain statistical parameters," Int. J. Veh. Struct. Syst., vol. 8, no. 3, p. 167, (2016).

12. N. G. Nikolaou and I. A. Antoniadis, "Rolling element bearing fault diagnosis using wavelet packets," Ndt E Int., vol. 35, no. 3, pp. 197-205, (2002).

13. J. Zarei and J. Poshtan, "Bearing fault detection using wavelet packet transform of induction motor stator current," Tribol. Int., vol. 40, no. 5, pp. 763-769, (2007).

14. A. Nabhan and A. Rashed, "Experimental and numerical investigation of defect-size estimation in taper roller bearing," Noise Vib. Worldw., vol. 49, no. 11, pp. 345-354, (2018).

15. G. Jiang, H. He, J. Yan, and P. Xie, "Multiscale convolutional neural networks for fault diagnosis of wind turbine gearbox," IEEE Trans. Ind. Electron., vol. 66, no. 4, pp. 3196-3207, (2018).

16. L. Wang, W. Ye, Y. Shao, and H. Xiao, "A new adaptive evolutionary digital filter based on alternately evolutionary rules for fault detection of gear tooth spalling," Mech. Syst. Signal Process., vol. 118, pp. 645-657, (2019).

17. V. Sharma and A. Parey, "Case study on the effectiveness of gear fault diagnosis technique for gear tooth defects under fluctuating speed," IET Renew. Power Gener., vol. 11, no. 14, pp. 1841-1849, (2017).

18. J. Park, J. M. Ha, H. Oh, B. D. Youn, J.-H. Choi, and N. H. Kim, "Model-based fault diagnosis of a planetary gear: A novel approach using transmission error," IEEE Trans. Reliab., vol. 65, no. 4, pp. 1830-1841, (2016).

19. N. Ghazaly, A. Kamel, and M. O. Mousa, "Influence of misalignment and backlash on spur gear using fem," Int. J. Mech. Prod. Eng., vol. 2, no. 12, pp. 2092-2320, (2014).

20. A. Bulushi, G. R. Rameshkumar, and M. Lokesha, "Fault diagnosis in belts using time and frequency based signal processing techniques," Int. J. Multidiscip. Sci. Eng., vol. 6, no. 11, pp. 12-20, (2015).

21. S. Ojha, D. Sarangi, B. K. Pal, and B. B. Biswal, "Performance monitoring of vibration in belt conveyor system," J. Eng. Res. Appl., vol. 4, no. 7, pp. 22-31, (2014).

22. A. Nabhan, M. R. El-Sharkawy, and A. Rashed, "Monitoring of Belt-Drive Defects Using the Vibration Signals and Simulation Models," Int. J. Aerosp. Mech. Eng., vol. 13, no. 5, pp. 332339, (2019).

23. M. J. Leamy and T. M. Wasfy, "Transient and steady-state dynamic finite element modeling of belt-drives," J. Dyn. Sys., Meas., Control, vol. 124, no. 4, pp. 575-581, (2002).

24. M. J. Leamy, "On a perturbation method for the analysis of unsteady belt-drive operation," Trans. ASME, vol. 72, pp. 570-580, (2005).

25. A. K. Ameer, A. Nabhan, R. Mohamed, and A. Rashed, "Dynamic Model Analysis for Unsteady Operating of Double V-Belt Drive System," Turkish J. Comput. Math. Educ., vol. 12, no. 14, pp. 2950-2963, (2021).

26. A. Nabhan, A. Rashed, A. K. Ameer, and M. Bakrey, "Diagnosing and Monitoring of Double V-Belt Drive System Under Unsteady Operating Conditions Via DMA," Int. J. Mech. Mechatronics Eng., vol. 21, no. 3, pp. 1-10, (2021).

27. M. Yang, Early Fault Detection Scheme and Optimized CBM Strategy for Gear Transmission System Operating under Varying Loads. University of Toronto, (2011).

28. A. J. McEvily, "Failures in inspection procedures: case studies," Eng. Fail. Anal., vol. 11, no. 2, pp. 167-176, (2004). 
29. [29] M. Zekveld and G. P. Hancke, "Vibration condition monitoring using machine learning," in IECON 2018-44th Annual Conference of the IEEE Industrial Electronics Society, pp. 4742-4747, (2018).

30. K. Van Den Abeele, J. Carmeliet, and M. Wevers, "Quantification of microdamage in slate tiles: comparison of nonlinear acoustic resonance experiments with visual and $\mathrm{X}$-ray diagnosis," in AIP Conference Proceedings, vol. 524, no. 1, pp. 307-310, (2000).

31. R. E. Green, "Basic wave analysis of acoustic emission," in Mechanics of nondestructive testing, Springer, pp. 55-76, (1980).

32. C. Scheer, W. Reimche, and F.-W. Bach, "Early fault detection at gear units by acoustic emission and wavelet analysis," J. Acoust. Emiss, vol. 25, pp. 331-340, (2007).

33. T. J. Hoskins, K. D. Dearn, S. N. Kukureka, and D. Walton, "Acoustic noise from polymer gears-A tribological investigation,” Mater. Des., vol. 32, no. 6, pp. 3509-3515, (2011).

34. M. Amarnath and S.-K. Lee, "Assessment of surface contact fatigue failure in a spur geared system based on the tribological and vibration parameter analysis," Measurement, vol. 76, pp. 32-44, (2015).

35. S. Ebersbach, Z. Peng, and N. J. Kessissoglou, "The investigation of the condition and faults of a spur gearbox using vibration and wear debris analysis techniques," Wear, vol. 260, no. 12, pp. 16-24, (2006).

36. M. Henneberg, B. Jørgensen, and R. L. Eriksen, "Oil condition monitoring of gears onboard ships using a regression approach for multivariate T2 control charts," J. Process Control, vol. 46, pp. 1-10, (2016).

37. C. P. Nemarich, H. K. Whitesel, and A. Sarkady, "On-line wear particle monitoring based on ultrasonic detection and discrimination," David Taylor Research Center Bethesda Md Propulsion And Auxiliary Systems Dept, (1988).

38. R. R. Whitlock, "X-Ray Methods for Monitoring Machinery Condition," Adv. X-Ray Anal., vol. 40, (1997).

39. D. G. Lewicki and D. M. Blanchette, "Evaluation of an oil-debris monitoring device for use in helicopter transmissions," National Aeronautics And Space Administration Cleveland Oh Lewis Research Center, (1992).

40. P. J. Dempsey, "A comparison of vibration and oil debris gear damage detection methods applied to pitting damage," (2000).

41. P. J. Dempsey, Gear damage detection using oil debris analysis. National Aeronautics and Space Administration, Glenn Research Center, (2001).

42. P. J. Dempsey, D. G. Lewicki, and H. J. Decker, "Investigation of gear and bearing fatigue damage using debris particle distributions," National Aeronautics And Space Administration Cleveland Oh Glenn Research Center, (2004).

43. A. Nabhan and M. O. Mousa, "Bearing fault detection techniques-a review," Turkish Journal of Engineering, Sciences and Technology, Vol. 3(2), (2015).

44. J. Yi and P. D. Quinonez, "Gear surface temperature monitoring," Proc. Inst. Mech. Eng. Part J J. Eng. Tribol., vol. 219, no. 2, pp. 99-105, (2005).

45. A. Korde, "On-line condition monitoring of motors using electrical signature analysis," in Recent Advances in Condition-Based Plant Maintenance. In Seminar Organized by Indian Institute of Plant Engineers, Mumbai, India, vol. 1718 , (2002).

46. A. Kumar, C. P. Gandhi, Y. Zhou, R. Kumar, and J. Xiang, "Latest developments in gear defect diagnosis and prognosis: A review," Measurement, vol. 158, p. 107735, (2020).

47. S.-L. Chang, Y.-Z. Lin, and W.-C. Chen, "Visual Inspection System for the Spur Gears," Int. J. Mech. Aeronaut. Eng., vol. 1, no. 1, pp. 17-22, (2017).

48. X. Ben Wei, W. Zheng, and R. Lin, "Design of LabView-based system of noise measurement on gear box," in Advanced Materials Research, vol. 328, pp. 2167-2171, (2011).

49. G. Park, K. Kabeya, H. H. Cudney, and D. J. Inman, "Impedance-based structural health monitoring for temperature varying applications," JSME Int. J. Ser. A Solid Mech. Mater. Eng., vol. 42, no. 2, pp. 249-258, (1999).

50. C. Kar and A. R. Mohanty, "Monitoring gear vibrations through motor current signature analysis and wavelet transform," Mech. Syst. Signal Process., vol. 20, no. 1, pp. 158-187, (2006).

51. S. Aouabdi, M. Taibi, S. Bouras, and N. Boutasseta, "Using multi-scale entropy and principal component analysis to monitor gears degradation via the motor current signature analysis," Mech. Syst. Signal Process., vol. 90, pp. 298-316, (2017). 
52. A. D. Dimarogonas and C. A. Papadopoulos, "Crack detection in turbine rotors," in Proceedings of 2nd International Symposium on Transport Phenomena Dynamics and Design of Rotating Machinery, Honolulu, Hawaii, April, pp. 3-6, (1988).

53. R. M. Warner, Spectral analysis of time-series data. Guilford Press, (1998).

54. A. K. S. Jardine, D. Lin, and D. Banjevic, "A review on machinery diagnostics and prognostics implementing condition-based maintenance," Mech. Syst. Signal Process., vol. 20, no. 7, pp. 1483-1510, (2006).

55. O. D. Mohammed, "Dynamic modelling and vibration analysis for gear tooth crack detection." Luleå tekniska universitet, (2015).

56. O. D. Mohammed and M. Rantatalo, "Gear fault models and dynamics-based modelling for gear fault detection-a review," Eng. Fail. Anal., p. 104798, (2020).

57. A. Aherwar, "An investigation on gearbox fault detection using vibration analysis techniques: A review," Aust. J. Mech. Eng., vol. 10, no. 2, pp. 169-183, (2012).

58. H. M. Ali et al., "Experimental Analysis of Tooth Breakage Effect on the Vibration Characteristics of Spur Gears," Tech. J., vol. 23, no. 01, pp. 42-52, (2018).

59. L. Cui, T. Yao, Y. Zhang, X. Gong, and C. Kang, "Application of pattern recognition in gear faults based on the matching pursuit of a characteristic waveform," Measurement, vol. 104, pp. 212-222, (2017).

60. A. S. Sait and Y. I. Sharaf-Eldeen, "A review of gearbox condition monitoring based on vibration analysis techniques diagnostics and prognostics," Rotating Mach. Struct. Heal. Monit. Shock Vib. Vol. 5, pp. 307-324, (2011).

61. A. Nabhan, A., Rashed, "Detection of Localized Fault in Inner Race of Deep Groove Ball Bearing Based on MSC-ADAMS,” J. Egypt. Soc. Tribol., vol. 17, no. 2, pp. 23-39, (2020).

62. M. Surányi, C. Reinbrecht, and H. Huemer, "Experimental study of failing differential gears and introduction of a new condition indicator for ultra low speed applications," Mech. Syst. Signal Process., vol. 155, p. 107588, (2021).

63. M. Lebold, K. McClintic, R. Campbell, C. Byington, and K. Maynard, "Review of vibration analysis methods for gearbox diagnostics and prognostics," in Proceedings of the 54th meeting of the society for machinery failure prevention technology, vol. 634, p. 16, (2000).

64. M. A. Khan et al., "Gear misalignment diagnosis using statistical features of vibration and airborne sound spectrums," Measurement, vol. 145, pp. 419-435, (2019).

65. P. D. Samuel and D. J. Pines, "A review of vibration-based techniques for helicopter transmission diagnostics," J. Sound Vib., vol. 282, no. 1-2, pp. 475-508, (2005).

66. J. J. Zakrajsek, "NASA Technical Memorandum 102340," Lewis Res. Center, Cleveland, OH.

67. B. D. Forrester, "Advanced vibration analysis techniques for fault detection and diagnosis in geared transmission systems." Swinburne University of Technology Melbourne, VIC, Australia, (1996).

68. I. Atoui, H. Meradi, R. Boulkroune, and R. Saidi, "Fault detection and diagnosis in rotating machinery by vibration monitoring using FFT and Wavelet techniques," in 2013 8th international workshop on systems, signal processing and their applications (WoSSPA), pp. 401-406, (2013).

69. A. Soheili, J. Sadeh, and R. Bakhshi, "Modified FFT based high impedance fault detection technique considering distribution non-linear loads: Simulation and experimental data analysis," Int. J. Electr. Power Energy Syst., vol. 94, pp. 124-140, (2018).

70. G. Dalpiaz, A. Rivola, and R. Rubini, "Gear fault monitoring: comparison of vibration analysis techniques," in Proceedings of the 3rd International Conference on Acoustical and Vibratory Surveillance Methods and Diagnostic Techniques, vol. 13, pp. 623-637, (1998).

71. N. Rinanto et al., "Rotor bars fault detection by DFT spectral analysis and Extreme Learning Machine," in 2016 International Symposium on Electronics and Smart Devices (ISESD), pp. 103-108, (2016).

72. F. K. Choy, H. Chen, and J. Zhou, "Identification of single and multiple teeth damage in a gear transmission system," Tribol. Trans., vol. 49, no. 3, pp. 297-304, (2006).

73. M. M. R. Taha, A. Noureldin, J. L. Lucero, and T. J. Baca, "Wavelet transform for structural health monitoring: a compendium of uses and features," Struct. Heal. Monit., vol. 5, no. 3, pp. 267-295, (2006).

74. J. Sanz, R. Perera, and C. Huerta, "Gear dynamics monitoring using discrete wavelet transformation and multi-layer perceptron neural networks," Appl. Soft Comput., vol. 12, no. 9, pp. 2867-2878, (2012). 
75. L. Mann, A. Saxena, and G. M. Knapp, "Statistical- based or condition- based preventive maintenance?," J. Qual. Maint. Eng., (1995).

76. W. Caesarendra, M. Pratama, B. Kosasih, T. Tjahjowidodo, and A. Glowacz, "Parsimonious network based on a fuzzy inference system (PANFIS) for time series feature prediction of low speed slew bearing prognosis," Appl. Sci., vol. 8, no. 12, p. 2656, (2018).

77. Y. Wang, Z. Wei, and J. Yang, "Feature trend extraction and adaptive density peaks search for intelligent fault diagnosis of machines," IEEE Trans. Ind. Informatics, vol. 15, no. 1, pp. 105-115, (2018).

78. S. Bansal, S. Sahoo, R. Tiwari, and D. J. Bordoloi, "Multiclass fault diagnosis in gears using support vector machine algorithms based on frequency domain data," Measurement, vol. 46, no. 9, pp. 3469-3481, (2013).

79. G. Cheng, Y. Cheng, L. Shen, J. Qiu, and S. Zhang, "Gear fault identification based on Hilbert-Huang transform and SOM neural network," Measurement, vol. 46, no. 3, pp. 11371146, (2013).

80. L. Jing, M. Zhao, P. Li, and X. Xu, "A convolutional neural network based feature learning and fault diagnosis method for the condition monitoring of gearbox," Measurement, vol. 111, pp. 1-10, (2017).

81. H. Ma, X. Pang, R. Feng, R. Song, and B. Wen, "Fault features analysis of cracked gear considering the effects of the extended tooth contact," Eng. Fail. Anal., vol. 48, pp. 105-120, (2015).

82. H. J. Decker, Crack detection for aerospace quality spur gears. Defense Technical Information Center, (2002).

83. P. Večeř, M. Kreidl, and R. Šmíd, "Condition indicators for gearbox condition monitoring systems," Acta Polytech., vol. 45, no. 6, (2005).

84. C. J. Li and J. D. Limmer, "Model-based condition index for tracking gear wear and fatigue damage," Wear, vol. 241, no. 1, pp. 26-32, (2000).

85. S. Wu, M. J. Zuo, and A. Parey, "Simulation of spur gear dynamics and estimation of fault growth," J. Sound Vib., vol. 317, no. 3-5, pp. 608-624, (2008).

86. W. Wang, "Early detection of gear tooth cracking using the resonance demodulation technique," Mech. Syst. Signal Process., vol. 15, no. 5, pp. 887-903, (2001).

87. N. Haloui, D. Chikouche, and M. Benidir, "Diagnosis of gear systems by spectral analysis of vibration signals," Int. J. Comput. Sci. Netw. Secur., vol. 7, no. 10, pp. 285-293, (2007).

88. L. Nacib, S. Saad, and S. Sakhara, "A comparative study of various methods of gear faults diagnosis," J. Fail. Anal. Prev., vol. 14, no. 5, pp. 645-656, (2014).

89. I. A. Abu-Mahfouz, "A comparative study of three artificial neural networks for the detection and classification of gear faults," Int. J. Gen. Syst., vol. 34, no. 3, pp. 261-277, (2005).

90. D. Chen and W. J. Wang, "Classification of wavelet map patterns using multi-layer neural networks for gear fault detection," Mech. Syst. Signal Process., vol. 16, no. 4, pp. 695-704, (2002).

91. G. Cirrincione, R. R. Kumar, A. Mohammadi, S. H. Kia, P. Barbiero, and J. Ferretti, "Shallow versus deep neural networks in gear fault diagnosis," IEEE Trans. Energy Convers., vol. 35, no. 3, pp. 1338-1347, (2020).

92. $X$. Wang and V. Makis, "Autoregressive model-based gear shaft fault diagnosis using the Kolmogorov-Smirnov test," J. Sound Vib., vol. 327, no. 3-5, pp. 413-423, (2009).

93. X. Yang, K. Ding, and G. He, "Phenomenon-model-based AM-FM vibration mechanism of faulty spur gear,” Mech. Syst. Signal Process., vol. 134, p. 106366, 2019.

94. X. Liu, Y. Yang, and J. Zhang, "Resultant vibration signal model based fault diagnosis of a single stage planetary gear train with an incipient tooth crack on the sun gear," Renew. Energy, vol. 122, pp. 65-79, (2018).

95. H. Chen, Y. Sun, Z. Shi, and J. Lin, "Intelligent analysis method of gear faults based on FRWT and SVM," Shock Vib., vol. 2016, (2016).

96. N. Saravanan, V. N. S. K. Siddabattuni, and K. I. Ramachandran, "Fault diagnosis of spur bevel gear box using artificial neural network (ANN), and proximal support vector machine (PSVM)," Appl. Soft Comput., vol. 10, no. 1, pp. 344-360, (2010).

97. Z. Xing, J. Qu, Y. Chai, Q. Tang, and Y. Zhou, "Gear fault diagnosis under variable conditions with intrinsic time-scale decomposition-singular value decomposition and support vector machine," J. Mech. Sci. Technol., vol. 31, no. 2, pp. 545-553, (2017). 
98. Z. Qiang, G. Jieying, L. Junming, T. Ying, and Z. Shilei, "Gearbox fault diagnosis using data fusion based on self-organizing map neural network," Int. J. Distrib. Sens. Networks, vol. 16, no. 5, p. 1550147720923476, (2020).

99. W. Li, L. Zhang, and Y. Xu, "Gearbox pitting detection using linear discriminant analysis and distance preserving self-organizing map," IEEE International Instrumentation and Measurement Technology Conference Proceedings, pp. 2225-2229, (2012). 